\title{
VEGETATION DYNAMICS TREND USING SATELLITE TIME SERIES IMAGERY
}

\author{
Z. Najafi ${ }^{1}$, P. Fatehi ${ }^{2}$, A. A. Darvishsefat ${ }^{3}$ \\ ${ }^{1}$ M.Sc. student of forest management, Department of Forestry and Forest Economic, Faculty of Natural Resources, University of \\ Tehran, Karaj, Iran- zeynab.najafi@ut.ac.ir \\ ${ }^{2}$ Department of Forestry and Forest Economic, Faculty of Natural Resources, University of Tehran, Karaj, Iran- \\ parviz.fatehi@ut.ac.ir \\ ${ }^{3}$ Department of Forestry and Forest Economic, Faculty of Natural Resources, University of Tehran, Karaj, Iran- \\ adarvish@ut.ac.ir
}

Keywords: Vegetation dynamic; Time Series; Mann-Kendall; NDVI; Regression; Theil-Sen

\begin{abstract}
:
In this study, the trend of vegetation dynamics in Kermanshah city assessed using NDVI MOD13Q1 product over the time period of 2000-2017. Based on time series imagery the pick of vegetation phenology stage (maximum NDVI) identified, then the trend of vegetation dynamic was investigated using the Ordinary Least Square regression and the Theil-Sen approaches. To generate a pixel-wise trend map, a pixel-based vegetation dynamics was also implemented. A non-parametric Mann-Kendall statistics approach was used to examine a statistically significant trend analysis. The mean maximum NDVI observed for the first half or second half of April. Trend analysis using regression and Theil-Sen methods indicated a no-trend in vegetation fractions. The pixel-based trend assessment using regression showed that a $50 \%$ of the study area faced a positive trend and reaming part faced a negative trend. The Theil-Sen method revealed the no-trend for a large majority of area. The Mann-Kendall test indicated that only 20 percent of the area shows a statistically significant trend.
\end{abstract}

\section{INTRODUCTION}

Urban green spaces play a vital role in creating the proper living conditions and activities for urban communities with diverse environmental, social, cultural, economic, and aesthetic functions. Vegetation covers, similar to other ecosystem components, are interacting with their biological and non-biological agents over time, and rarely remain unchanged (Yang et al., 2012; De Jong et al., 2013). Vegetation changes act as a driver for changing habitat and cause disturbance in ecosystem conditions and performances. Nowadays, one of the most important issues in the environmental topics is changing in vegetation condition (Rannow and Neubert, 2014). Therefore, detecting and evaluating of vegetation changes as a key step in determining the driver forces and recognizing the mechanism of change with the aim of ensuring sustainable management and optimal use of essential resources are critical (Abbas Zadeh Tehrani and Saberi, 2013; Arakhy, 2012). This study amid to evaluate the trend of Total vegetation dynamics over the Kermanshah city during the period of 2000-2017 using the normalized difference vegetation index (NDVI) obtained from MODIS imagery (MOD13Q1 16-day dataset). It is important to mention that, in this study we focused on the vegetation dynamics that can be caused by climatic changing or environmental factors.

\section{LITERATURE REVIEW}

Several studies attempted to assess vegetation dynamics based on remotely sensed imagery. For example; Kiapasha et al. (2017) studied the trend of long-term vegetation changes and its relationship with temperature and precipitation variables throughout the Hyrcanian forests. In this study, 15-day composite NDVI dataset (in total 756 images) obtained from NOAA and climate data, i.e. temperature and precipitation, were used during 1981-2012. The results showed a greening trend in the most parts of the study area (75.35\%). Kermani et al. (2017) investigated the trend of vegetation changes in the Turan protected area using MODIS vegetation time series from 2001 to 2015. The results revealed that a $44 \%$ of the study area was without trend, $26 \%$ with a positive trend and $30 \%$ with a negative trend. Yin et al. (2016) studied the vegetation dynamics and the correlation of vegetation and climate variables from 1982 to 2012 over the Central Asia. The GIMMS (Global Inventory Modeling and Mapping Studies) NDVI product and climate data were used. The results indicated that NDVI showed a positive correlation with the precipitation and a weak negative correlation with the temperature. Sun et al. (2015) assessed vegetation dynamics and its relationship with climate change using the time series GIMMS NDVI product obtained from 1982 to 2006 in northern China. The results indicated a slight 
increase in the vegetation fraction over the past 25 years. Correlation between NDVI and climatic data showed a higher correlation between NDVI and temperature compared to the precipitation.

\section{MATERIALS \& METHODS}

\subsection{Study area}

The study area, Kermanshah city (figure 1), is located in the West of Iran at approximately $34^{\circ} 41^{\prime} \mathrm{N}$, $47^{\circ} 00^{\mathrm{E}} .47^{\circ} 00 \mathrm{E}$ (upper left) and lower right $34^{\circ} 35^{\mathrm{N}}$, $47^{\circ} 30 \mathrm{E}$. Kermanshah, the capital of Kermanshah Province, is one of the major metropolises in Iran.

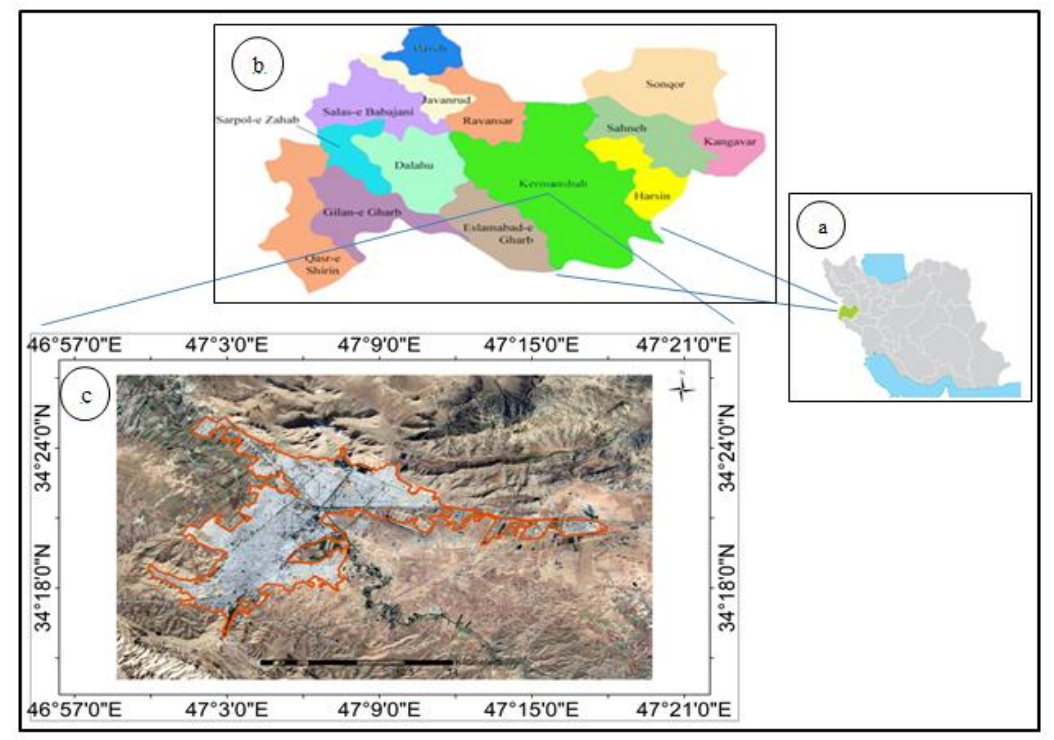

Figure 1. Location of study area: (a) in Iran, (b) in the Kermanshah province, and (c) in the Kermanshah city (background: Google Earth image)

\subsection{Data}

The Moderate Resolution Imaging Spectrometer (MODIS) NDVI datasets (i.e. MOD13Q1 product) were analyzed in this study. The NDVI time series of 16-day composites from 2000 to 2017 at a spatial resolution of 250 meter were gathered. In order to focus on the highest phenological period, we used only the NDVI dataset captured over the spring season. In total, 108 NDVI images were considered for further analysis. A raster layer covering the Kermanshah city territory was used to clip the time series dataset.

\subsection{Methods}

\subsubsection{Temporal variation in the peak of vegetation phenology}

The 16-day NDVI composites of spring season for each year were analyzed. First, a threshold value of 0.2 implemented to determine the vegetated pixels (Huang et al., 2016). Then, a spring seasonal average NDVI was calculated for the all-corresponding pixels (i.e. vegetated pixels over the Kermanshah city). Finally, the image with the highest average value of NDVI for each year was selected to study the trend dynamics analysis over the time series.

\subsubsection{Trend analysis}

Different approaches were applied to characterize changes in the long-term maximum NDVI time series. We used a parametric technique, i.e. Ordinary Least Square (OLS) regression, and a non-parametric technique i.e. Theil-Sen regression approach. In both techniques, the NDVI and time were considered as dependent and independent variables, respectively.

\subsubsection{OLS}

One of the simplest and the most common time series analysis methods is the ordinary least square (OLS) regression. This is a parametric method which requires the variables to be normally distributed. A simple linear regression is as follows:

$$
\mathrm{Y}=\mathrm{a}+\mathrm{bX}
$$

Where $X$ is an independent variable, $Y$ is a dependent variable and $a$ and $b$ are regression coefficients that are 
computed using the least squares method (Ghahreman \& Gharekhani, 2010).

\subsubsection{Theil-Sen}

Theil-Sen regression approach is a non-parametric statistical method that is used to estimate the magnitude of the trend. Contrary to the parametric approaches, Theil-Sen does not need a prior assumption about distribution of data and perform better than the parametric approaches for the short time series (Yang et al., 2018). The basis of this method is to calculate the median slope between each pairwise combination over time.

The slope of $N$ pairs of data $\left(Q_{k}\right)$ are first computed as:

$$
Q_{k}=\frac{x_{j}-x_{i}}{j-i} \text { for } k=1, \ldots, N
$$

Where $x_{i}$ and $x_{j}$ are the data values at times $j$ and $i(j>i)$, respectively.

And then the median of $N$ values of $Q_{k}\left(Q_{m e d}\right)$ is calculated as (Zewdie et al., 2017):

$$
Q_{\text {med }}= \begin{cases}Q_{\left[\frac{N+1}{2}\right]} & \text { if } N \text { is odd } \\ 1 / 2\left(Q_{\left[\frac{N}{2}\right]}+Q_{\left[\frac{N+2}{2}\right]}\right) & \text { if } N \text { is even }\end{cases}
$$

Furthermore, the pixel-based trends were investigated using mentioned methods.

To evaluate the significant $(P<0.05)$ of trend The MannKendall trend test was implemented. The Mann-Kendall trend test is a non-parametric statistical approach that widely used for environmental trend analysis. Currently, MK method is applied for testing the significance of changes in NDVI (Zewdie et al., 2017). The Mann-Kendall time series statistic $(S)$ is calculated as:

$$
\mathrm{S}=\sum_{\mathrm{i}=1}^{\mathrm{n}-1} \sum_{\mathrm{j}=\mathrm{i}+1}^{\mathrm{n}} \operatorname{sgn}\left(\mathrm{x}_{\mathrm{j}}-\mathrm{x}_{\mathrm{i}}\right)
$$

Where $n$ is the number of observations, $x_{i}$ and $x_{j}$ are the observations at times $i$ and $j$, respectively. The $\operatorname{sgn}\left(x_{j}-x_{i}\right)$ is the sign function as follow:

$$
\operatorname{Sgn}\left(x_{j}-x_{i}\right)= \begin{cases}+1 & \text { if } \quad\left(x_{j}-x_{i}\right)>0 \\ 0 & \text { if } \quad\left(x_{j}-x_{i}\right)=0 \\ -1 & \text { if } \quad\left(x_{j}-x_{i}\right)<0\end{cases}
$$

Where the sample size $n>10$, the variance of $S$ computed by:

$$
\operatorname{Var}(S)=\frac{n(n-1)(2 n+5)-\sum_{i=1}^{m} t_{i}\left(t_{i}-1\right)\left(2 t_{i}+5\right)}{18}
$$

Where $m$ is the number of tied groups, and $t_{i}$ denotes the size of extent $i$. The standardized $Z$ test statistics following a normal standardized distribution as follow:

$$
Z_{S}=\left\{\begin{array}{llc}
\frac{S-1}{\sqrt{\operatorname{Var}(S)}} & \text { if } & \mathrm{S}>0 \\
0 & \text { if } & \mathrm{S}=0 \\
\frac{S+1}{\sqrt{\operatorname{Var}(S)}} & \text { if } & \mathrm{S}<0
\end{array}\right.
$$

The positive sign of $Z_{s}$ indicates increasing trends, and the negative value shows decreasing trends. A significant test is determined based on comparing result of $Z$ value with $Z_{1}$ a/2 from the standard normal distribution table at alpha significance level. Whereas the following equation is established, the trend is statistically significant (Yurekli, 2015).

$$
\left|Z_{s}\right|>Z_{\alpha / 2}
$$

\section{RESULTS}

\subsection{Maximum vegetation fraction date}

Figure 2 illustrates that the mean NDVI values were reached to their maximum mostly on the first half of April, and on the second half of April.

\subsection{Long-term changes in the maximum vegetation fraction}

According to the figure 3 the results of the mean NDVI trend analysis using the least squares regression and the Theil-Sen approaches showed almost no-trend with a slope of zero. 


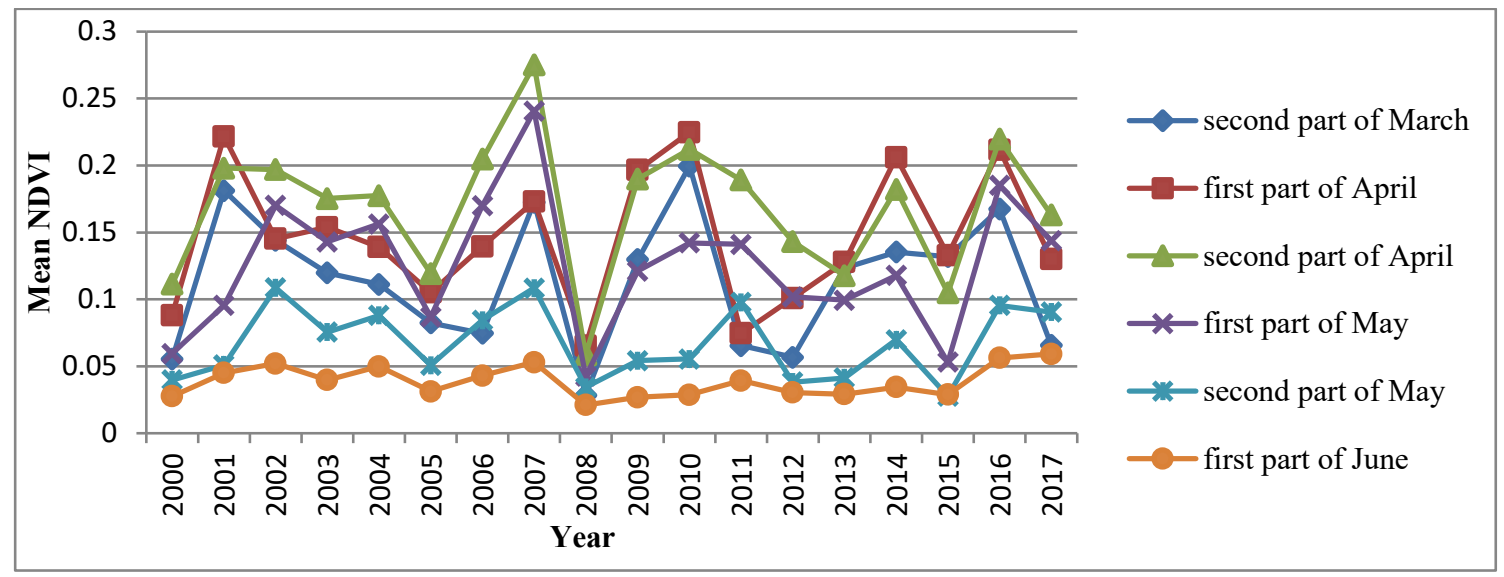

Figure 2. Vegetation dynamics in 16-day NDVI composite for spring season during 2000-2017
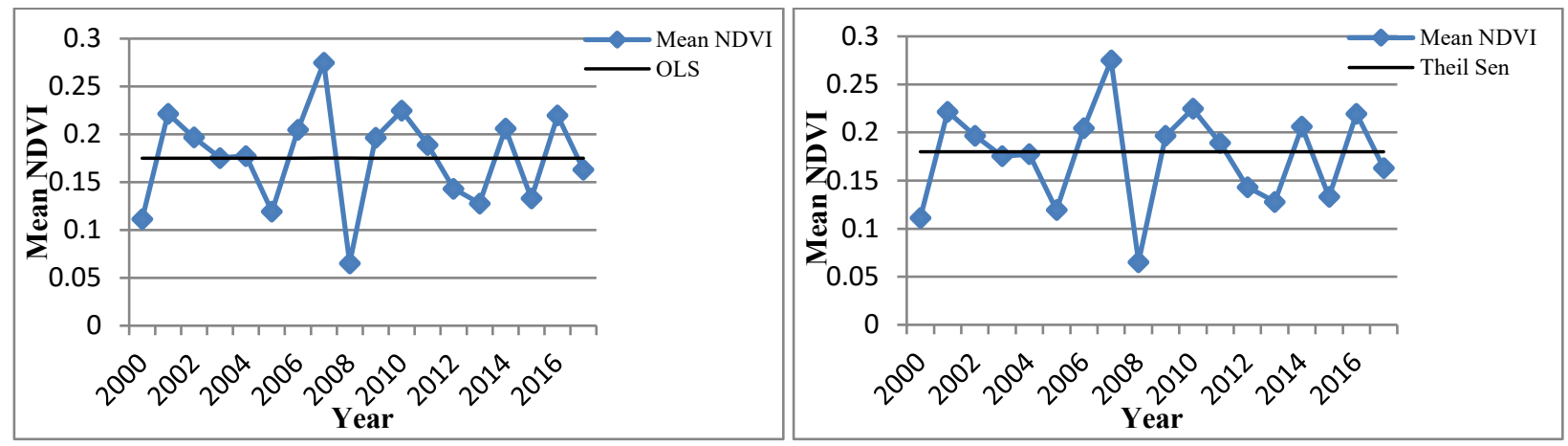

Figure 3. NDVI trend variation using OLS and Theil-Sen methods during 2000-2017

\subsection{Pixel-based long-term analysis}

Figure 4 illustrates the results of trend assessment using OLS (a), Theil-Sen (b) and significant trend test using Mann-Kendall (c) approaches. According to table 1, trend assessment of the NDVI variation using OLS

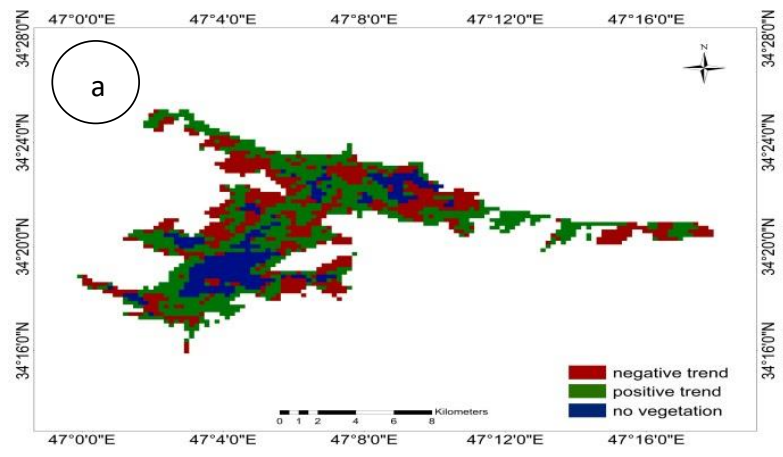

approximately showed a positive trend in the fifty percent of the study area and remaining part faced with a negative trend. In contrast, the Theil-Sen method showed a no-trend for a large majority of area. The Mann-Kendall test indicated that only 20 percent of the area shows a statistically significant trend.

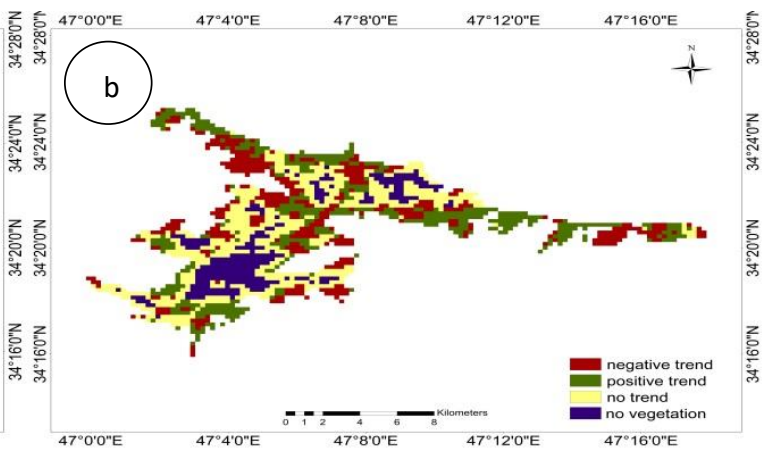




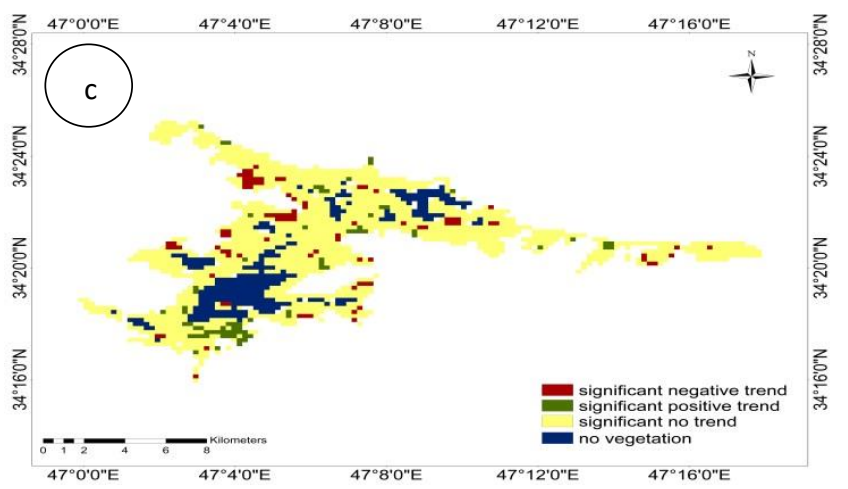

Figure 4. Spatial patterns of vegetation dynamic trends using OLS (a), Theil-Sen (b) and Mann-Kendall trend test (c)

Table 1. Quantitative results of applied vegetation dynamic trends aproaches.

\begin{tabular}{|c|c|c|c|}
\hline Trend estimators & OLS & Theil-Sen & Mann-Kendall \\
\hline Percent of negative trend area & 44.10 & 29.66 & 4.77 \\
\hline Percent of positive trend area & 55.90 & 31.46 & 6.06 \\
\hline Percent of no trend area & 0 & 38.88 & 89.17 \\
\hline
\end{tabular}

\section{CONCLUSIONS}

The maximum mean vegetation in the Kermanshah city has changed during the study period, with a maximum and minimum difference of $78.69 \%$. However, the results of mean NDVI long-term trend analysis over Kermanshah city indicated no trend using the OLS and Theil-Sen approaches over 2000-2017. Pixel based trend assessment generated from OLS and Theil-Sen approaches showed almost positive trend in half of the study site and in the other showed the negative trend. Whereas, Mann-Kendall significant trend approach showed that the 20 percent of the trends are statistically significant. In order to provide more information on vegetation dynamics and help to define the best management strategy, investigating the relevance between vegetation cover and its drivers i.e. climate data seems necessary in the future studies.

\section{REFERENCES}

Abbaszade tehrani, N, and Saberi, N., 2012. Seasonal land cover change assessment using remote sensing data analysis. Proceedings of 3th International Conference on Environmental Planning \& Management. Tehran. (in Persian).

Arkhi, S., Niaz, Y., Adibnejad, M., 2011. Vegetation monitoring using remote sensing techniques in Ilam Dam Basin. Journal of Geography and Development. 24, 121136. (in Persian).

De Jong, R., Verbesselt, J., Schaepman, M. E., De Bruin, S., 2012. Trend changes in global greening and browning: contribution of short-term trends to longer-term change. Global Change Biology, 18(2), 642-655.

Gharekhani, A, and, Ghahreman, N., 2010. Seasonal and annual trend of relative humidity and dew point temprature in several climatic regions of Iran. Journal of Water and Soil, 24(4), 636-646.

Huang, H., Chen, Y., Clinton, N., Wang, J., Wang, X., Liu, C., Gong, P., Yang, J., Bai, Y., Zheng, Y., Zheng, Y., Zhu, Z., 2017. Mapping major land cover dynamics in Beijing using all Landsat images in Google Earth Engine. Remote Sensing of Environment, 202, 166-176.

Kermani, F., Rayegani, B., Nezami, B., Goshtasb, H., Khosravi, H., 2017. Assessing the vegetation trends in arid and semi-arid regions (Case study: Touran Protected Area). Journal of the Ecosystem of Desert Engineering, 6(16), 114. (in Persian).

Kiapasha, K., Darnishsefat, A.A., Zargham, N., Attarod, P., Nadi, M., Schaepman, M.E., 2017. Greening trend in the Hyrcanian forests using NOAA NDVI time series during 1981-2012. Journal of Forest and Wood Products, 70(3), 409-420. (in Persian).

Rannow, S, and Neubert, M., 2014. Managing protected areas in central and eastern Europe under climate change. $322 \mathrm{p}$.

Sun, Y., Yang, Y., Zhang, Y., Wang, Z., 2015. Assessing vegetation dynamics and their relationships with climatic variability in northern China. Physics and Chemistry of the Earth, Parts A/B/C, 87, 79-86. 
Yang, J., Weisberg, P.J., Bristow, N.A., 2012. Landsat remote sensing approaches for monitoring long-term tree cover dynamics in semi-arid woodlands: Comparison of vegetation indices and spectral mixture analysis. Remote Sensing of Environment, 119, 62-71.

Yin, G., Hu, Z., Chen, X., Tiyip, T., 2016. Vegetation dynamics and its response to climate change in Central Asia. Journal of Arid Land, 8(3), 375-388.

Yang, Q., Huang, X., Tang, Q., (2019). The footprint of urban heat island effect in 302 Chinese cities: Temporal trends and associated factors. Science of the Total Environment, 655, 652-662.

Yürekli, K., (2015). Impact of climate variability on precipitation in the upper Euphrates-Tigris rivers basin of southeast Turkey. Atmospheric Research, 154, 25-38.

Zewdie, W., Csaplovics, E., Inostroza, L., (2017). Monitoring ecosystem dynamics in northwestern Ethiopia using NDVI and climate variables to assess long term trends in dryland vegetation variability. Applied geography, 79, 167-178. 